\title{
Prevalence of Refractive Error and Attitude to Spectacle Use among Drivers of Public Institutions in Ibadan, Nigeria
}

\author{
${ }^{1}$ C. O. Bekibele, ${ }^{2}$ O. I. Fawole, ${ }^{2}$ A. E. Bamgboye, ${ }^{2}$ L. V. Adekunle, \\ ${ }^{3}$ R. Ajayi and ${ }^{1}$ A. M. Baiyeroju \\ ${ }^{1}$ Department of Ophthalmology, ${ }^{2}$ Department of Epidemiology, Medical Statistics, and Environmental Health, \\ College of Medicine, and ${ }^{3}$ University Staff Clinic Services, University of Ibadan, Ibadan, Nigeria \\ Reprint requests to: Charles O. Bekibele, Department of Ophthalmology, College of Medicine, University of \\ Ibadan, Ibadan, Nigeria. E-mail: Cob150@yahoo.com
}

\begin{abstract}
Background: High rate of motor vehicle accidents have been associated with poor vision. Studies on drivers from elsewhere other than health institutions have found abnormal visual acuities. The aim of this study is to determine prevalence of refractive errors and the attitude to spectacle wear among drivers of public institutions studied.

Methods: A cross sectional population study of all 99 motor vehicle drivers from the College of Medicine, University of Ibadan and University College Hospital (UCH) Ibadan between December 2003 and January 2004.

Results: The ninety-nine motor vehicle drivers in the study comprised of $67(67.7 \%)$ from the College of Medicine, and $32(32.3 \%)$ from the UCH. All were males, aged 38 to 60 years, mean $50.1 \pm(\mathrm{SD}=4.8$ years). Proportion of drivers with refractive errors was $16.7 \%$ (95\% CI, 16.6-16.8) but only $56.3 \%$ of these wear glasses while driving (others did not including 3 out 4 who were bilaterally visually impaired without glasses). Relative frequency of RTA among drivers was $16.2 \%$, the risk was marginally higher among drivers with refractive error (OR 1.2, 95\% CI: 0.4-3.7). The commonest refractive error was simple hypermetropia present in 15 eyes. Hypermetropia was associated with increasing age of drivers $(p<0.05)$. Majority $(97.7 \%)$ of the drivers were presbyopic but only $32(32.3 \%)$ were current wearers of spectacles.

Conclusion: Refractive errors were present in $16.7 \%$ of drivers studied. But $43.8 \%$ of these (3 out 4 of whom were bilaterally visually impaired without glasses) do not wear corrective lenses while driving. There is need for periodic visual screening exercise and eye health education on drivers.
\end{abstract}

Key words: Hypermetropia, astigmatism, drivers, refractive error

\begin{abstract}
Résumé
Introduction: Taux élevé des accidents de la circulation routière est associé à une mauvaise vision. Des études sur les chauffeurs ailleurs en déhors des centres hospitaliers ont indiqué des acuités visuelles anormales. L'objet de cette étude est de décider la fréquence d'erreurs de réfraction et le comportement par rapport à l'utilisation des lunettes parmi des chauffeurs dans des institutions publiques.

Méthodes: Une étude d'un groupe représentatif de la population de tous le 99 chauffeurs des voitures du Collège hospitaliter universitaire d'Ibadan et du Collège de la médicine, Université d'Ibadan entre décembre 2003 et janvier 2004.

Résultats: Quatre-vingt dix-neuf chauffeurs des vehicles dans cette étude à savoir, 67 soit 67,7\% de Collège de la médicine, et 32 soit 32,3\% de CHU. Tous étaient du sexe masculin, âgés de 38 au 60 ans, moyen $50,1+-(\mathrm{SD}=4,8$ ans) La proportion des chauffeurs avec erreurs de réfraction était $16,7 \%$ soit $95 \% \mathrm{cl}, 16,6$ - 16,8) mais seulement $56,3 \%$ de ceux qui portent des lunettes pendant qu'il conduissent (les autres ne le fait pas y compris 3 sur 4 qui sont bilatéralement des personnes qui ont des problèmes de vue sans des lunettes) fréquence rélative de ACR parmi des chauffeurs était 16,2\%. Le danger est presque plus élevé parmi des chauffeurs avec des erreurs de réfraction (OR 1, 2,95\% cl ; 0,4 - 3,7). L'erreur de réfraction le plus ordinaire était tout simplement l'hypermétropie qui est present dans 15 yeux. L'ypermétropie était associeé à l'augmentation de l'âge des chauffeurs $(\mathrm{P}<0,05)$ La majorité soit $97,7 \%$ des chauffeurs étaient presbyopique mais seulement 32 soit 32,3\% étaient des porteurs actuel des lunettes.
\end{abstract}


Conclusion: Errurs de réfraction étaient present en 16,7\% des chauffeurs étudiés. Mais 43,8\% de ceuxci (3 entre 4 dont était bilatéralement des personnes qui ont des problèmes de vue sans de lunettes) ne portent pas des lunettes quand ils conduissent. C'est nécessaire de faire un dépistage visuel périodique et créer une renseignment médicale sur les yeux pour des chauffeurs

Mots-clés: Hypermétropie astigmatism, chauffeur réfrective

\section{Introduction}

Recent studies have shown an increase in the rate of road traffic accidents (RTA) in many developing and developed countries. ${ }^{1}$ The situation in Nigeria is such that many lives are lost daily through motor vehicle accidents. ${ }^{2}$ Studies have also shown a strong relationship between RTAs and drivers vision. ${ }^{3}$ In a vision survey by Nwosu ${ }^{4}$ on 719 civil servant motor vehicle drivers in Oyo state, Nigeria the prevalence of subnormal vision was $3.1 \%$, and monocular blindness $2.4 \%$. Refractive errors were present in $20.2 \%$. The study also reported a statistically significant association between road traffic accident and subnormal vision. In another survey of Nigerian Navy personnel in Ojo Lagos, ${ }^{5}$ in 1991, it was discovered that refractive errors were present in $47.9 \%$ of those examined with only half of these requiring presbyopic spectacle correction. Motor vehicle accidents due to poor vision related to underlying refractive errors can easily be prevented if identified and treated with out sequel.

The policy in most government establishments is to carry out pre-employment examination of new employees routinely including eye examinations for drivers. This screening exercise provides opportunity to identify drivers with uncorrected refractive errors who are subsequently treated. However there is dearth of information about the driver's attitude to the use of spectacles once prescribed and employment commenced. Also, after the pre-employment examination, periodic eye examinations are usually not done except when an individual develops eye problems. There has been no study on the prevalence of refractive errors in a large educational institution such as the College of Medicine. This study therefore aims at determining the prevalence of refractive errors and the attitude to spectacle wear among drivers of the College of Medicine University of Ibadan (UI) and the University College Hospital (UCH) so as to make suggestions to improve eye health of drivers in the public sector.

\section{Materials and Methods}

This is a cross sectional survey, carried out at the Eye Clinic, of the University College Hospital Ibadan over a 2 months period (December 2003 and January 2004). Subjects were all 102 motor vehicle drivers employed by the College of Medicine, UI and the $\mathrm{UCH}$, Ibadan. Both institutions are located within the same premises in Ibadan but are under different management structure. The management of the University of Ibadan is subject to the Federal Ministry of Education while the management of the hospital is subject to the Federal Ministry of Health.

Ethical approval was obtained from the UI/UCH joint institutional review committee before the commencement of the study._Subjects were recruited by formal invitation through the respective heads of department, the university health service, University of Ibadan and the University College Hospital, Ibadan. Every participant was given a voluntary consent form after thorough explanation of the procedure involved. All drivers consented to participate in the study but eventually 3 of them did not show up. Subjects were interviewed using a standard semi-structured self-administered questionnaire. Questions asked included sociodemograhic characteristics including age (names were excluded to ensure confidentiality), marital status, religion and level of education, driving experience, history of road traffic accidents directly involving the driver while driving, the duration and type of glasses worn while driving if any, current and previous eye complaints or diseases.

Eye examination was carried out by only the principal investigator (an ophthalmologist) and this eliminated inter observer error. Examination included a measurement of visual acuity in both eyes and examination of the eyes with torchlight, then a direct ophthalmoscope. Refraction was done using a Keeler streak retinoscope followed by objective refraction to determine the presence of underlying refractive error (defined as presenting vision less than 6/9 and improved with the aid of a minimum of 0.50 diopter lenses ${ }^{7}$ ) and presbyopia (difficulty seeing near in those aged 40 years or more and correctable with convex lenses of 1 diopters or more). However only eyes with visual acuity $<6 / 18$ were considered to be visually impaired in line with International Statistical Classification of Diseases and related Health problems, tenth revision (ICD-10). ${ }^{6}$

The data generated was coded, entered into a personal computer using facilities in the Statistical Package for Social Sciences (SPSS) version 10.0. Frequency tables and proportions were used for data summarization and presentation of qualitative data. While means and standard deviations were used for quantitative data.

\section{Results}

A total of 102 motor vehicle drivers were recruited into the study comprising of $67(67.7 \%)$ from the College of Medicine, and 32 (32.3\%) from the UCH. There were 3 defaulters giving a response rate of $97.1 \%$. 
The drivers were all males aged 38 - 60 years, (mean $50.1 \pm$ SD 4.8 years). Eighty-two $(82.8 \%)$ had primary 6 leaving certificate while $17(17.2 \%)$ had secondary education. All drivers had professional driving licence, with driving experience ranging from 5 years to 43 years, mean 27.94 years \pm (SD 6.2). Prevalence of RTA among the drivers was $16.2 \%$.

None of the drivers involved in the study was bilaterally blind. However 97 (97.7\%) had poor near visual acuity due to presbyopia. This was easily corrected with presbyopic spectacles. Four $(4 \%)$ had uncorrected bilateral visual acuity of between 6/24$6 / 60$ (category 1 visual impairment in ICD-10) ${ }^{6}$. With refraction however no driver remained bilaterally visually impaired. Seven $(7.1 \%)$ had unaided visual acuity of between $6 / 24$ and $6 / 60$ in their right eyes, with refraction however they all improved to between $6 / 6$ and 6/12 leaving no right eye visually impaired. With unaided vision 6 left eyes $(6 \%)$ were visually impaired while $2(2 \%)$ were considered blind. Four out of 6 eyes with unaided vision of between $6 / 24$ and $6 / 60$ were improved by refraction leaving only 2 visually impaired left eyes that could not be improved by refraction. One out of the 2 eyes with unaided vision of $1 / 60$ and LP respectively, initially considered blind had its vision improved after refraction leaving only $1(1 \%)$ blind eye, which could not be corrected. Table 1 shows the visual status of the motor vehicle drivers in this study. Refractive error was therefore the commonest cause of bilateral visual impairment and was present in 4 drivers (of whom only 3 admitted to wearing glasses for driving). It was also the commonest cause of visual impairment in the right eyes of 7 drivers, and the commonest cause of visually impaired left eye in 5 of the 8 left eyes with visual impairment. Other causes of visually impaired or blind left eyes included cataract alone $2(2 \%)$, and cataract with optic atrophy $1(1 \%)$.

The proportion of drivers with refractive errors was therefore $16.7 \%$ (95 \% CI, 16.6-16.8) but only $56.3 \%$ of these wear glasses while driving. The risk of having RTA among those drivers with refractive error was marginally higher than those with out, with $18.8 \%$ of those with errors compared to $15.7 \%$ with out having RTA (OR 1.2, 95\% CI: 0.4-3.7; P>0.05). The commonest type of refractive error was simple hypermetropia present in 15 eyes $((7.8 \%)$; this was followed by hypermetropic atigmatism present in 6 eyes $(3.0 \%)$. Less common refractive errors were myopia and aphakia. There was a statistically significant association between hypermetropia and increasing age of the drivers $(\mathrm{P}<0.05)$. The distribution of the different types of refractive errors is as shown in tables 2 and 3. Majority $(97.7 \%)$ of the drivers were presbyopic but only $32(32,3 \%)$ were current wearers of spectacles while $67.7 \%$ had never worn one before. The range of duration of spectacle wear was 0-11years, mean 1.1+(SD 2.18). 20.2\% wore reading glasses only while $11.1 \%$ wore combined reading and distance spectacles. Presbyopic corrections ranged from $+125-+3$ dioptres, with over $75 \%$ of the subjects requiring $+175-2.75$ Dioptres.

Table 1: Visual status of the drivers

\begin{tabular}{lllll}
\hline Visual acuity & Right eye & & Left eye & \\
\hline & Unaided $(\%)$ & Refracted $(\%)$ & Unaided $(\%)$ & Refracted $(\%)$ \\
\cline { 2 - 5 } $6 / 6-6 / 18$ & $92(92.9)$ & $99(100)$ & $91(91.9)$ & $96(97.0)$ \\
$6 / 24-6 / 60$ & $7(7.1)$ & - & $6(6.0)$ & $2(2.0)$ \\
$<6 / 60-3 / 60$ & - & - & - & - \\
$<3 / 60-1 / 60$ & - & - & $1(1.0)$ & - \\
LP - NLP & - & - & $1(1.0)$ & $1(1.0)$ \\
\hline Total & $99(100)$ & $99(100)$ & $99(100)$ & $99(100)$ \\
\hline
\end{tabular}

LP: light perception; NLP: no light perception

Table 2: Refractive errors amongst the drivers

\begin{tabular}{|c|c|c|c|c|}
\hline Dioptric power & Hypermetropia (\%) & Myopia (\%) & Astigmatism (\%) & \\
\hline & & & With the rule & Against the rule \\
\hline $0.50-1.50$ & $16(8.1)$ & - & $1(0.5)$ & $6(3.0)$ \\
\hline $2.0-3.0$ & $5(2.5)$ & - & - & - \\
\hline$\geq 10$ & $1(0.5)$ & $1(0.5)$ & - & - \\
\hline Total & $22(11.1)$ & $1(0.5)$ & $1(0.5)$ & $6(3.0)$ \\
\hline
\end{tabular}

Table 3: Association of hypermetropia with advancing drivers' age

\begin{tabular}{llll}
\hline Driver's age (years) & No refractive error (\%) & Hypermetropia (\%) & Total (\%) \\
\hline$<50$ & $49(92.5)$ & $4(7.5)$ & $53(100)$ \\
$\geq 50$ & $30(75)$ & $10(25)$ & $40(100)$ \\
\hline Total & $79(84.9)$ & $14(15.1)$ & $93(100)$ \\
\hline$X^{2}=9.9 ; \mathrm{p}<0.05$ & & \\
\hline
\end{tabular}




\section{Discussion}

The fact that some of the drivers examined had uncorrected visual impairment in both or either eye due to refractive errors goes to show the importance of periodic visual screening exercise. The finding of $16.7 \%$ for refractive errors was slightly lower than $20.2 \%$ observed for drivers in Oyo State public service. ${ }^{4}$ This could be due to the selective group of these drivers who work within the hospital environment. In the Blue mountains ${ }^{7}$ eye study to determine factors associated with under-corrected refractive errors in an older population, undercorrected refractive error was present in only $10.2 \%$ of the studied population and drivers were found to be less likely to have under-corrected refraction. This was believed to be due to a greater motivation by older drivers to maintain good distance vision in other to retain their driver's licence during re-certification for drivers licence. In many developing countries ${ }^{4}$ however visual standards are not fixed and screening tests for certification and re-certification are not regularly done thus encouraging drivers to take their sight for granted, this may there fore explain the high prevalence of uncorrected presenting vision among the drivers studied. This is distressing bearing in mind the slightly higher proportion of RTA among those found to have refractive errors. There is therefore need for introduction and enforcement of minimal visual standards for the purpose of certification and re-certification for drivers licence in Nigeria and other developing countries.

The need for health education is indicated by the low frequency of use of spectacles amongst those with refractive errors. It is not clear why many of those who required glasses denied the use but one impression obtained from the drivers during the interview was that wearing glasses was a sign that some thing was wrong with their eyes and this could in some way affect their driving. This again shows the need for targeted education on motor vehicle drivers. In a study to determine barriers to wearing of glasses among primary school children in Lagos, Nigeria, cost implications and lack of information about the function of glasses by the parents were important considerations. ${ }^{8}$

The predominance of hypermetropia amongst the drivers studied compares with findings by Nworah and Ezepue ${ }^{9}$ who also documented predominance of hypermetropia among patients of a Nigerian Eye clinic. The prevalence of hypermetropia among the drivers with an average age of 50.1years is also in keeping with increasing trend towards hypermetropia with increasing age among the patients studied by Olurin, ${ }^{10}$ and Nwosu ${ }^{11}$. Myopia of mild to moderate degree were however uncommon among the drivers except for one surprise case of pathological myopia among the drivers. It is worthy of note that Olurin, ${ }^{10}$ Ositelu $^{12}$ and Adegbehingbe ${ }^{13}$ all reported myopia as the commonest refractive error among patients from Western Nigeria where this was conducted, however their patients were much younger (mean age 35.9, 29.5) than the drivers in this study. Increasing hypermetropia with age occurs due to two main reasons: ${ }^{14}$ increased refractive index of the cortex makes the whole lens more homogenous and with less converging power and the eye becomes more hypermetropic; secondly is an apparent increase of hypermetropia with age due to progressive failure of accommodation, as the tone of the cilliary muscle decreases, some of the latent hypermetropia becomes manifest. Thus the age difference may have been responsible for the variability of findings between this study and the previous studies irrespective of the similarity in genetic origin of the studied populations. $^{15}$

Our definition of refractive error i.e. presenting vision less than 6/9 improved with the aid of a minimum of 0.50 diopter lenses ${ }^{7}$ may be considered high but it was the definition used by a similar but international study, 'the Blue Mountains Eye study in Australia'. Using a less stringent definition would have left out many potential cases with underlying refractive error. However our definition of visual impairment $(<6 / 18)$ was in line with the International Statistical Classification of Diseases and related Health problems, tenth revision (ICD-10). ${ }^{6}$ We also realize there must have been much underreporting / concealment of RTA history by the drivers for fear of losing their jobs. We could find no reliable verification of the facts since many had been known to conceal RTA from their superiors in the past.

This study has observed that $16.7 \%$ of the drivers studied had underlying refractive errors, but $43.8 \%$ of these (3 out 4 of whom were bilaterally visually impaired with out glasses) do not wear corrective lenses while driving. This goes to show the importance of visual screening exercise and targeted eye health education on this special group of people.

\section{Acknowledgments}

The authors are grateful to the managements of the College of Medicine, University of I badan and the University College Hospital for giving permission for the study on their drivers. This study was carried out with personal funding only.

\section{Reference}

1. Oyemade A. Epidemiology of road traffic accidents in Ibadan and its environs. Nigerian Medical Journal 1973; 3:174-177

2. Asogwa SE. Road traffic accidents: a major public health problem in Nigeria. Publ Hlth 1978; 92: 237-245

3. Humphries D. Three South African studies on the relation between road accidents and drivers' vision. Ophthalmic Physiol Opt 1987; 7:73-79

4. Nwosu SNN. Vision survey of government motor vehicle drivers in Oyo State. National postgraduate Medical College of Nigeria, Lagos, 1989

5. Uweche P. Pattern of eye diseases in naval 
personnel seen in the Nigerian navy hospital Ojo, Lagos. National Postgraduate Medical College of Nigeria, Lagos, 1991

6. Thylefors B, Negrel AD, Pararajasegaram R, Dadzie KY. Global data on blindness. Bull WHO 1995; 73: 115-121

7. Thiagalingam S, Cumining RG, Mitchell P. Factors associated with under corrected refractive errors in an older population: The blue maintain eye study. Br J Ophthalmol 2002 ; 86:1041-1045

8. Faderin MA, Ajaiyeoba AI. Barriers to wearing glasses among primary school children in Lagos, Nigeria. Nigerian Journal of Ophthalmology 2001; 9:15-19

9. Nworah PB, Ezepue UF. Prevalence of errors of refraction in a Nigerian eye clinic. Orient Journal of Medicine (Nigeria) 1992; 4:57-60
10. Olurin O. Refractive errors in Nigeria: a hospital clinic study. Ann Ophthalmol 1973; 5: 971-976

11. Nwosu SNN. Ametropia in Onitsha, Nigeria. Nigerian Journal of Ophthalmology 1997; 5:2124

12. Adefule-Ositelu AO. Refractive errors in Lagos, Nigeria. Nigerian Medical Journal1995; 29:101103

13. Adegbeingbe BO, Majekodunmi AA, Akinsola FB, Soetan EO. Pattern of refractive errors at Obafemi Awolowo University Teaching Hospital, Ile-Ife, Nigeria. Nigerian Journal of Ophthalmology 2003; 11:76-79

14. Abrams D. Duke Elder's practice of refraction. Churchill Livingstone, Edinburgh, 1993; 45

15. Optics, refraction and contact lenses. Basic and Clinical Science Course 2001-2002; section 3: 122-126 